IMECE2012-89235

\title{
A DIFFUSION MODEL IN A TWO-PHASE INTERFACIAL ZONE FOR NANOSCALE LITHIUM-ION BATTERY MATERIALS
}

\author{
Cheng-Kai ChiuHuang \\ North Carolina State University \\ Department of Mechanical \& Aerospace Engineering \\ Raleigh, North Carolina, USA \\ cchiuhu@ncsu.edu
}

\author{
Hsiao-Ying Shadow Huang* \\ North Carolina State University \\ Department of Mechanical \& Aerospace Engineering \\ Raleigh, North Carolina, USA \\ hshuang@ncsu.edu
}

\begin{abstract}
The development of lithium-ion batteries plays an important role to stimulate electric vehicle (EV) and plug-in electric vehicle (PHEV) industries and it is one of many solutions to reduce US oil import dependence. To develop advanced vehicle technologies that use energy more efficiently, retaining the lithium-ion battery capacity is one of major challenges facing by the electrochemical community today. During electrochemical processes, lithium ions diffuse from and insert into nanoscaled cathode materials in which stresses are formed. It is considered that diffusion-induced stress is one of the factors causing electrode material capacity loss and failure. In this study, we present a model which is capable for describing diffusion mechanisms and stress formation in nanoplatelike cathode materials, $\mathrm{LiFePO}_{4}$ (Lithium-iron-phosphate). We consider particle size $>100 \mathrm{~nm}$ in this study since it has been suggested that very small nanoparticles $(<100 \mathrm{~nm})$ may not undergo phase separation during fast diffusion. To evaluate diffusion-induced stress accurately, factors such as the diffusivity and phase boundary movements are considered. Our result provides quantitative lithium concentrations inside LiFePO ${ }_{4}$ nanoparticles. The result could be used for evaluating stress formation and provides potential cues for precursors of capacity loss in lithium-ion batteries. This study contributes to the fundamental understanding of lithium ion diffusion in electrode materials, and results from this model help better electrode materials design in lithium-ion batteries.
\end{abstract}

\section{INTRODUCTION}

To meet the goal of reducing total U.S. greenhouse gas emissions to $17 \%$ below 2005 levels by 2020 and $83 \%$ by 2050 [1], and to double the U.S. fuel efficiency standard from 27.3 miles per gallon in 2011 to 54.5 miles per gallon by 2025 [2], advancing lithium-ion battery technology for EVs/PHEVs is of paramount importance. Furthermore, decreasing the dependence on foreign oil is critical for national economy and security for the Unite States. Today, the United States imports $50-60 \%$ of the total oil consumption in which transportation sector accounts for nearly $72 \%$ in 2010 [3, 4]. Therefore, the development of PHEVs/EVs will significantly reduces both the petroleum consumption and greenhouse gas emissions. The main constituents of a lithium-ion battery include cathode, anode, separator and electrolyte. During charging and discharging, $\mathrm{Li}^{+}$extract/intercalate into the nanoscaled cathode, accompanied with the transport of electrons through current collector (Fig. 1). Lithium-ion batteries are currently selected as the energy storage device for PHEVs/EVs due to the high energy density (around $150 \mathrm{Wh} / \mathrm{kg}$ compared to $50 \mathrm{Wh} / \mathrm{kg}$ of Cd-Ni batteries) [5, 6]. However, retaining the lithium-ion battery capacity is one of major challenges facing by the electrochemical community today.

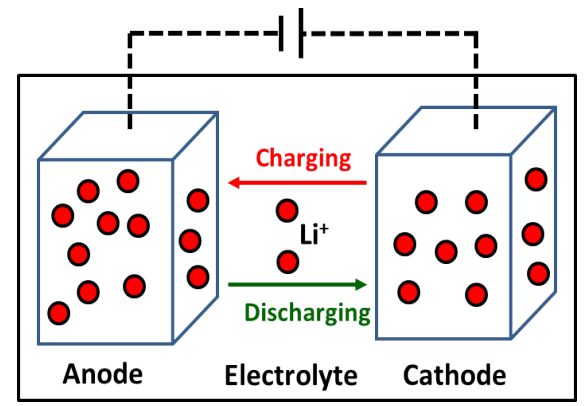

Figure 1. During charging/discharging, lithium ions extract from and insert into cathode materials while electrons go through the external wire to provide needed electricity.

The transport of $\mathrm{Li}^{+}$in electrode materials is a diffusion process. $\mathrm{Li}^{+}$diffusion in cathode materials is usually accompanied with the phase transformation, which leads to internal strain resulted from different lattice constants of different phases. Diffusion induced stress via $\mathrm{Li}^{+}$extraction and insertion is considered as one of the factors causing electrode failures and capacity loss. Capacity loss is found in several conditions: (1) High charging/discharging rate: $23.5 \%$ capacity loss while discharging rate increases from $2 \mathrm{C}$ to $50 \mathrm{C}$ 
[6], where the charging/discharging rate of $\mathrm{nC}$ represents that the battery is fully charged/discharged in $1 / \mathrm{n}$ hour. (2) Long period of cycling: $15.5 \%$ capacity loss after 600 cycles at $25^{\circ} \mathrm{C}$ is observed [7]. A mathematical model delineating $\mathrm{Li}^{+}$diffusion behavior and stress formation based on the experimental data gathered from different techniques such as in situ neutron scattering, scanning electron microscope (SEM), and transmission electron microscopy (TEM) is necessary, to better provide a mechanistic understanding of battery capacity loss and its relationships to particle fractures.

\section{General characteristics of $\mathrm{LiFePO}_{4}$ cathode materials}

Among several cathode materials, the olivine-based $\mathrm{LiFePO}_{4}$ with an orthorhombic crystal structure provide excellent characteristics for the application on EVs/PHEVs, such as good thermal stability, abundant iron ore resource, low raw material cost and high theoretical energy density (170 $\mathrm{mAh} / \mathrm{g}$ ) [8]. However, electronic conductivity and diffusivity of $\mathrm{LiFePO}_{4}$ are considerably lower than that of $\mathrm{LiMn}_{2} \mathrm{O}_{4}$ and $\mathrm{LiCoO}_{2}$ materials $[9,10]$. These intrinsic disadvantages of $\mathrm{LiFePO}_{4}$ could be improved by the methods such as doping, carbon coating, nano-scale particle size, and synthesis control $[8,11-13]$. Unlike the two-dimensional $\mathrm{Li}^{+}$diffusion in $\mathrm{LiCoO}_{2}$ and three-dimensional $\mathrm{Li}^{+}$diffusion in $\mathrm{LiMn}_{2} \mathrm{O}_{4}, \mathrm{Li}^{+}$diffusion in $\mathrm{LiFePO}_{4}$ is one-dimensional along the b-axis, and it is confirmed by theoretical calculations and experimental results [14-17]. This feature makes diffusion coefficient becomes particle size-dependent since a one-dimensional diffusion channel could be easily blocked by point defects [18].

\section{Two-phase system in $\mathrm{LiFePO}_{4}$}

$\mathrm{LiFePO}_{4}$ exists as a two-phase system during charging and discharging: a lithium-rich $\left(\mathrm{LiFePO}_{4}\right)$ and a lithium-poor $\left(\mathrm{FePO}_{4}\right)$ phases. A two-phase system of $\mathrm{LiFePO}_{4}$ could be explained by the Gibbs phase rule: a single-phase region has the characteristic of varying potentials with different lithium concentrations, and a two-phase region would reveal a steady potential during charging/discharging [19]. It is observed the shrinkage of the voltage plateau is related to the decreased particle size, and it is the main reason that nano-sized $\mathrm{LiFePO}_{4}$ particles provide excellent kinetic behavior [20-22]. However, suppression of the phase separation and nucleation may occur in relatively small $(<100 \mathrm{~nm})$ nanoparticles [23-27]. In addition, studies have shown that the phase composition of $\mathrm{LiFePO}_{4}$ also depends on the temperature [28, 29]. Below $200{ }^{\circ} \mathrm{C}$, a mixture of phases of $\mathrm{LiFePO}_{4}$ and $\mathrm{FePO}_{4}$ exists in the system. Between $200^{\circ} \mathrm{C}$ to $350^{\circ} \mathrm{C}$, system transforms into a single $\mathrm{Li}_{\mathrm{x}} \mathrm{FePO}_{4}$ phase. Above $500^{\circ} \mathrm{C}$, material decomposes into a mixture of non-olivine phases. Due to different lattice constants of the $\mathrm{LiFePO}_{4}(\mathrm{a}=10.33 \AA, \mathrm{b}=6.01 \AA$, and $\mathrm{c}=4.69 \AA)$ and the $\mathrm{FePO}_{4}(\mathrm{a}=9.76 \AA, \mathrm{b}=5.75 \AA$, and $\mathrm{c}=4.75 \AA)$ [30], approximately $7 \sim 9 \%$ change of volume occurs during the phase transformation from $\mathrm{FePO}_{4}$ to $\mathrm{LiFePO}_{4}(5.8 \%$ and $4.5 \%$ expansion in the a- and b-axes, and $1.3 \%$ contraction in the caxis) (Fig. 2).

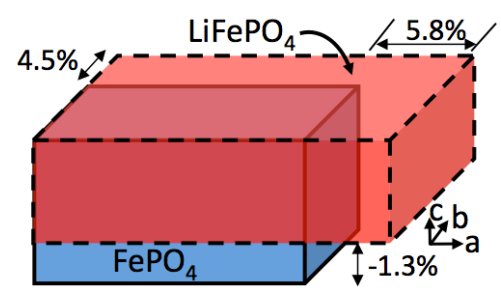

Figure 2. Volume change happens during phase transformation from $\mathrm{FePO}_{4}$ to $\mathrm{LiFePO}_{4}$ phases $(5.8 \%$ and $4.5 \%$ expansion in the a and $b$-axis, and $1.3 \%$ contraction in the c-axis).

Since $\mathrm{Li}^{+}$diffusion and phase transformation occur during charging/discharging in $\mathrm{LiFePO}_{4}$, one question that may arise: how the second phase is formed and how the phase boundary moves in a single particle. Tang et al. [31] have shown the effects of elastic energy during the phase transformation. They assume that the second phase is nucleated initially at the corner of the particle. $\mathrm{Li}^{+}$diffusion anisotropy and concentration growth in a single particle were studied. However, a diffused phase boundary was implicitly treated via the phase field method. On the other hand, Laffont et al. [32] have reported an interfacial zone with finite thickness between two phases in a partially lithiated/delithiated particle, where the occurance of the phase boundary is not limited to the edge or core of the particles. Moreover, Chen et al. [33] have observed the phase boundary via a high-resolution TEM, suggesting two phases are separated by a visible zone on the ac-plane. Such interfacial zone is observed in partially lithiated/delithiated particles with different lithium concentrations [33-35]. Nevertheless, detailed $\mathrm{Li}^{+}$diffusion behavior inside the interfacial zone and the concomitant phase boundary movement have not yet to be carefully addressed.

In the current study, we focus on the phase boundary movement which is driven by the lithium-ion concentration distribution inside the interfacial zone, specially, for particles larger than $100-\mathrm{nm}$. The phase transformation mechanism in smaller particles $(<100 \mathrm{~nm})$ is still under debate due to difficulties of in-situ observations [23-27]. For example, Chen et al. observed chemically delithidated $\mathrm{LiFePO}_{4}$ particles with particle size of $4-\mu \mathrm{m} \times 2-\mu \mathrm{m} \times 0.2-\mu \mathrm{m}$ [33]. TEM images reveal that both $\mathrm{LiFePO}_{4}$ and $\mathrm{FePO}_{4}$ phases present on the acplane in a $\mathrm{Li}_{0.5} \mathrm{FePO}_{4}$ particle by electron diffraction experiments. Based on this finding, they speculate that dislocation lines pile up along the c-axis, and nucleate into a phase boundary. Delmas et al. [36] have proposed a "dominocascade" model to describe the phase boundary movement along the a-axis during charging/discharging. The interface is limited to one block, therefore, either a fully lithiated or an unlithiated phase exists in a partially discharged $\mathrm{LiFePO}_{4}$ particle. That is, a diffused and transit interfacial zone was not considered in the domino-cascade model. According to the model, the phase boundary movement is caused by the unstable interfacial zone due to misfit strain. However, this model is later questioned because experiment results reveal the coexistence of $\mathrm{FePO}_{4}$ and $\mathrm{LiFePO}_{4}$ phases in a single particle, where stripe-like juxtaposed phase boundaries are observed 
[27, 32-35]. Moreover, a co-existing two-phase system under fast discharging was also computationally predicted by Cogswell and Bazant [37], Bai et al. [24], and Van der Ven et al. [38].

A two-phase interfacial zone in which $\mathrm{Li}^{+}$ insertion/extraction occurs is explicitly studied in the current study, in contrast to the studies by the phase-field method [31]. As such, the width of the interfacial zone is determined based on available experimental data. Laffont et al. [32] use a high resolution electron energy loss spectroscope to observe the twophase system of thin plate-like $\mathrm{LiFePO}_{4}$ particles with the average size about 200x100x50 nm. Experimental results show that the width of interfacial zone is $8 \sim 12 \mathrm{~nm}$ in a $172-\mathrm{nm}$ $\mathrm{Li}_{0.45} \mathrm{FePO}_{4}$ particle and $15 \sim 22 \mathrm{~nm}$ in a $170-\mathrm{nm} \mathrm{Li}_{0.26} \mathrm{FePO}_{4}$ particle, respectively. It is later concluded the size of the interfacial zone is approximately a constant and does not dependent on the particle size. Interestingly, their report on the existence of two interfacial zones in a single particle is not consistent with other studies, where only one phase boundary was found in a single particle [35]. Several research groups have demonstrated that coherency strain plays an important role in the phase boundary morphology, as well as the direction of phase boundary movement $[31,37-40]$. Results from the phasefield simulation show that the phase boundary is not perfectly parallel to bc-plane due to unequal coherent strains in three axes [31]. Nevertheless, the phase boundary movement is still considered along the a-axis. Though it is still unclear the location at which the phase transformation occurs in the particle, due to the difficulty of in-situ observations, the following two assumptions are widely accepted: (1) $\mathrm{Li}^{+}$ diffusion path in $\mathrm{LiFePO}_{4}$ particles could be considered as onedimensional and it is along the b-axis. (2) The phase boundary moves along the a-axis in $\mathrm{LiFePO}_{4}$ particles.

\section{A DIFFUSION MODEL IN A TWO-PHASE INTERFACIAL ZONE}

In the present study, we focus on lithium-ion diffusion in a two-phase interfacial zone within single particles. A nanosized plate-like $\mathrm{LiFePO}_{4}$ particle with the dimensions of $150 \mathrm{~nm} \mathrm{x}$ $60 \mathrm{~nm} \times 100 \mathrm{~nm}$ is selected in our model based on the experimentally measured particle size $[20,32] . \mathrm{LiFePO}_{4}$ crystal structure with eight unit cells is shown in Figure 3, whereas two neighboring $\mathrm{Li}$ atoms along the a-axis are $0.516-\mathrm{nm}$ apart [17]. As such, there are a total of 290 diffusion channels (150 $\mathrm{nm} / 0.516 \mathrm{~nm}=290)$ in each particle (Fig. 4a).

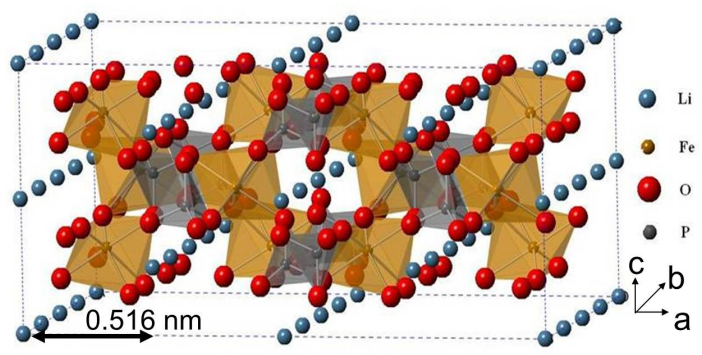

Figure 3. $\mathrm{LiFePO}_{4}$ crystal structure of eight unit cells.
For $\mathrm{LiFePO}_{4}$ cathode material, $\mathrm{Li}^{+}$diffusion is confined in the $\mathrm{b}$ direction in each channel. We consider the case that $\mathrm{LiFePO}_{4}$ phase is initially formed at the edge of the particle. Phase boundary moves along the a-axis while each channel is fully filled progressively along the a-direction. Therefore, timedependent $\mathrm{Li}^{+}$concentration along the b-axis in each channel could be individually represented by an equation of onedimensional Fick's second law (Eq. (1)) (Fig. 4b).

$$
\frac{\partial c_{i}(x, t)}{\partial t}=D_{i} \frac{\partial^{2} c_{i}(x, t)}{\partial x^{2}}
$$

where $c_{i}(x, t)$ represents $\mathrm{Li}^{+}$concentration in the $\mathrm{i}_{\mathrm{th}}$ channel, $\mathrm{D}_{\mathrm{i}}$ is the diffusivity $\left(\mathrm{cm}^{2} / \mathrm{s}\right)$ and $x$ is along with the b-axis.

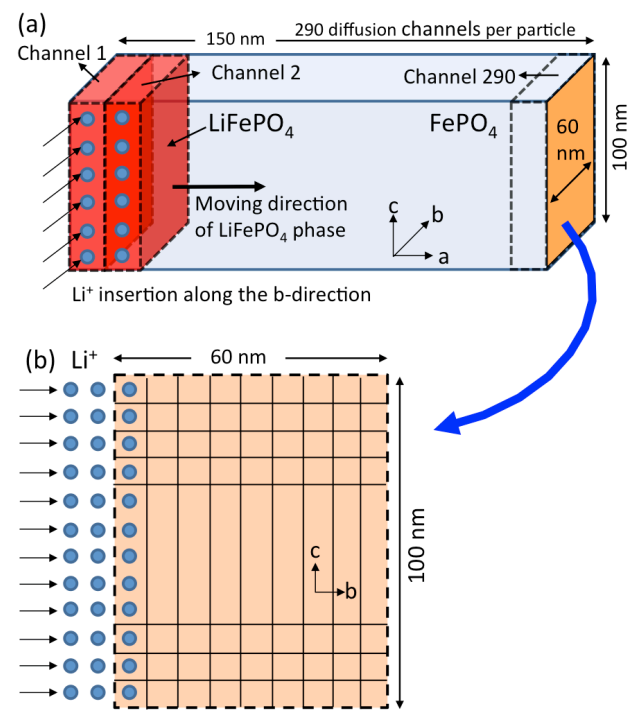

Figure 4. (a) Schematic view of a $\mathrm{Li}^{+}$diffusion model. During discharging, $\mathrm{LiFePO}_{4}$ phase moves along the a-direction. (b) View from the bc-plane. Diffusion channels with the length of $60 \mathrm{~nm}$.

\section{$\mathrm{Li}^{+}$diffusion in the interfacial zone}

The interfacial zone between $\mathrm{FePO}_{4}$ and $\mathrm{LiFePO}_{4}$ phases has the width of $4.2 \mathrm{~nm}$, according to available experimental data [32]. We consider that the $\mathrm{Li}^{+}$diffusion takes place in all channels at the same time with different diffusivities in different channel (Fig. 5a). Therefore, there are approximately 80 out of 290 diffusion channels in the interfacial zone $(4.2 \mathrm{~nm} / 0.516 \mathrm{~nm}=80)$.

Since the phase boundary movement is along the adirection, it is plausible to claim channels $\left(\mathrm{C}_{\mathrm{i}+1}\right)$ closer to the $\mathrm{LiFePO}_{4}$ phase exhibit higher diffusivities and reach maximum concentration values faster than others away from the $\mathrm{LiFePO}_{4}$ phase (Fig. 5b). We assume that the diffusivity in each channel in the interfacial zone decreases linearly from $\mathrm{D}_{\max }$ to zero (Fig. 5b). Therefore, channels $\left(\mathrm{C}_{\mathrm{i}+80}\right)$ closer to the $\mathrm{FePO}_{4}$ phase would have the lowest diffusivity. Once the channel $\mathrm{C}_{i+1}$ is fully filled, the interfacial zone moves one channel distance away in the a-direction and the interfacial zone moves from $\mathrm{C}_{\mathrm{i}+1} \sim \mathrm{C}_{\mathrm{i}+80}$ to $\mathrm{C}_{\mathrm{i}+2} \sim \mathrm{C}_{\mathrm{i}+81}$ (Fig. 5c). When the channel $\mathrm{C}_{\mathrm{i}+1}$ is fully filled, the diffusivity in the channel $\mathrm{C}_{\mathrm{i}+80}$ starts to increase, 
and the diffusivity in the channel $\mathrm{C}_{\mathrm{i}+81}$ remains zero in the interfacial zone (Fig. 5a).

During discharging, the $\mathrm{LiFePO}_{4}$ phase continues to grow along the a-axis while the interfacial zone finally reaches the channels $\mathrm{C}_{211} \sim \mathrm{C}_{290}$ (Fig. 6a). Further discharging decreases the interfacial zone until fully $\mathrm{LiFePO}_{4}$ phase is formed in the particle (Fig. 6b).
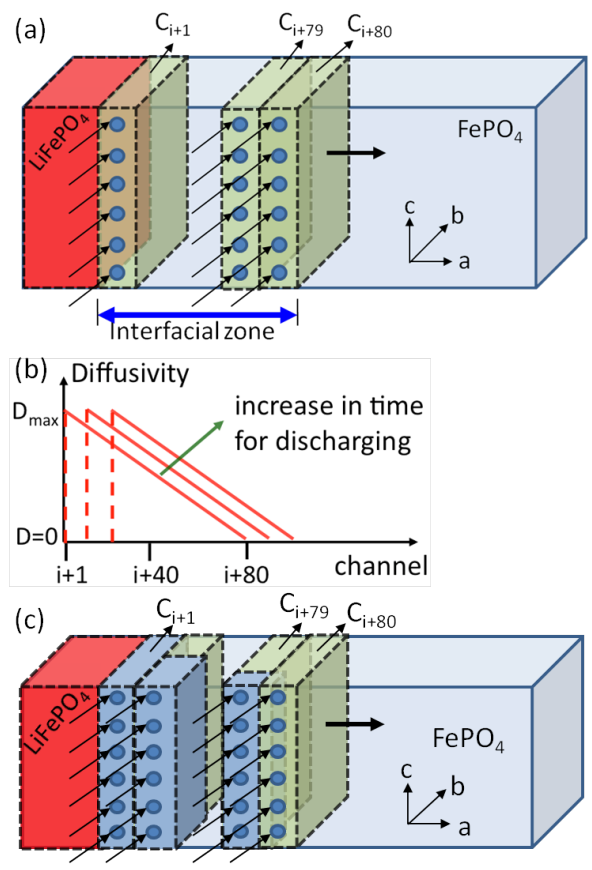

Figure 5. (a) The interfacial zone $(4.2 \mathrm{~nm})$ between the $\mathrm{LiFePO}_{4}$ and $\mathrm{FePO}_{4}$ phases. $\mathrm{C}_{\mathrm{i}+1} \sim \mathrm{C}_{i+80}$ represent the channel $\mathrm{i}+1$ to channel i+80. (b) The diffusivity in each channel in the interfacial zone (channel $C_{i+1} \sim C_{i+80}$ ) is assumed to decrease linearly from $D_{\max }$ to zero.

\section{Concentration profile within the interfacial zone}

The $\mathrm{Li}^{+}$concentration profile in each channel is derived by Eq. (1), where the concentration gradient is the main driving force. The effect of stress gradient is small compared to the concentration gradient [41], therefore it is not considered in our model system. Mathematica (Wolfram Research, Champaign, IL) is used for our numerical calculations. The diffusivity decreases linearly from $10^{-13}\left(\mathrm{~cm}^{2} / \mathrm{s}\right)$ to zero between channel $\mathrm{C}_{\mathrm{i}+1}$ to channel $\mathrm{C}_{\mathrm{i}+80}$, and the diffusion length in each channel is 60-nm long in the b-axis (Fig. 4b). When $\mathrm{t}=100$ seconds, none of channels are fully filled with lithium ions, and the channel $\mathrm{C}_{\mathrm{i}+1}$ has the highest concentration than the others due to higher diffusivity (Fig. 7a). The concentration profile in the channel $\mathrm{C}_{\mathrm{i}+80}$ remains zero because it is closer to the $\mathrm{FePO}_{4}$ phase, where the diffusivity approaches to zero. When $t=500$ seconds, the channel $\mathrm{C}_{\mathrm{i}+1}$ is fully filled with lithium-ions and the concentration in the channel $\mathrm{C}_{\mathrm{i}+40}$ is approximately equal to 0.8 $\mathrm{C}_{\max }$ (Fig. 7b). For time $>500$ seconds, $\mathrm{Li}^{+}$diffusion starts in the channel $\mathrm{C}_{\mathrm{i}+80}$ and the interfacial zone moves from $\mathrm{C}_{\mathrm{i}+1} \sim$ $\mathrm{C}_{\mathrm{i}+80}$ to $\mathrm{C}_{\mathrm{i}+2} \sim \mathrm{C}_{\mathrm{i}+81}$.
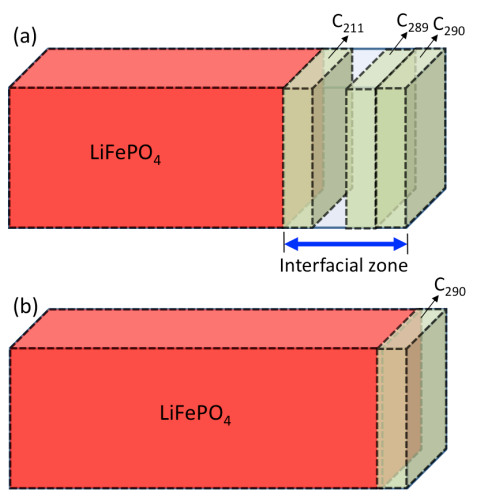

Figure 6. (a) During discharging, the $\mathrm{LiFePO}_{4}$ phase continues to grow along the a-axis. The interfacial zone reaches the channels $\mathrm{C}_{211} \sim \mathrm{C}_{290}$. (b) Further discharging decreases the interfacial zone until fully $\mathrm{LiFePO}_{4}$ phase is formed in the particle.

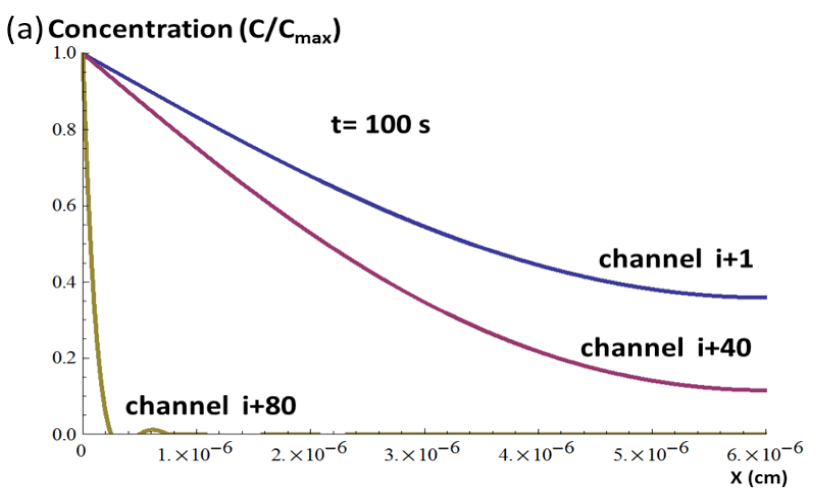

(b) Concentration ( $\left.\mathrm{C} / \mathrm{C}_{\max }\right)$

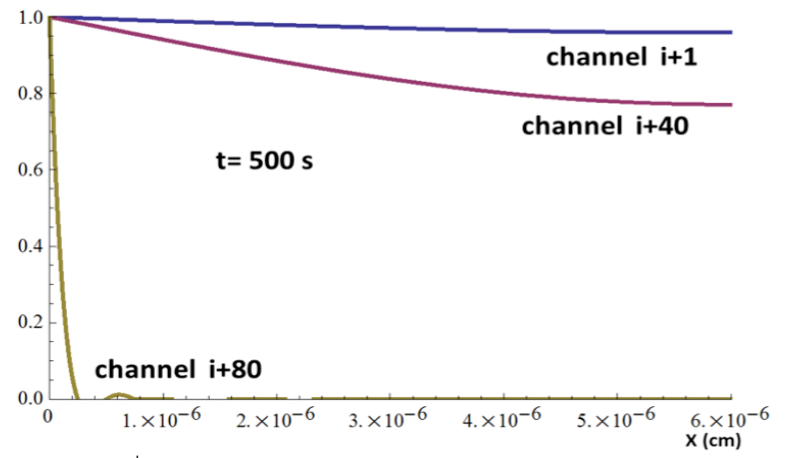

Figure 7. (a) $\mathrm{Li}^{+}$concentration profile in the interfacial zone. The channel $\mathrm{C}_{i+1}$ will be fully filled and become $\mathrm{LiFePO}_{4}$ phase first. (b) When $t=500$ seconds, the channel $C_{i+1}$ is fully filled with lithiumions and the concentration in the channel $C_{i+40}$ has reached 0.8 $\mathbf{C}_{\max }$.

Our model indicates channels are fully filled progressively, which is in consistent with the experimental results. Based on this approach, the time-dependent $\mathrm{Li}^{+}$concentration in $\mathrm{LiFePO}_{4}$ particles during discharging is derived. The model developed herein could be used to predict lithium concentrations at a certain location within a channel at an arbitrary state of discharge. Furthermore, the model could be expanded to predict concentration profiles while (dis)charging rate is increased. The predicted concentration values will later be used 
to develop a model to study diffusion-induced stresses in lithium-ion batteries.

\section{Diffusion induced stress in cathode materials}

The evaluation of diffusion-induced stress in a single $\mathrm{LiFePO}_{4}$ particle is one important research topic. Core-shell model (shrinking-core model) is the most commonly used approach to investigate the $\mathrm{Li}^{+}$concentration and diffusion induced stress in a single electrode particle [19, 42-46]. Some research groups investigate the stress in the elliptical particles and how the particle's aspect ratios affect stress values [41, 47, 48]. The concept of the core-shell model is that the second phase is initially formed from the shell while the phase boundary moves toward the core of the particle progressively. For example, when $\mathrm{Li}^{+}$inserts into a single $\mathrm{FePO}_{4}$ phase particle during discharging, the $\mathrm{LiFePO}_{4}$ phase will be initially formed in the shell while the core remains as a $\mathrm{FePO}_{4}$ phase (Fig. 8). The thickness of the shell becomes larger while the particle is under discharging. Upon fully discharged, the $\mathrm{Li}^{+}$ concentration will reach a maximum and the particle is composed of a single $\mathrm{LiFePO}_{4}$ phase.

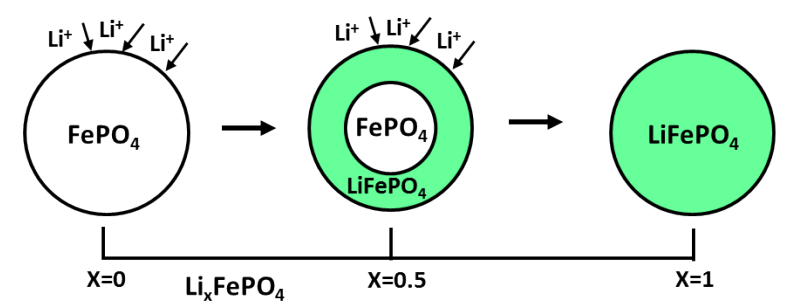

Figure 8. A shrinking-core model during discharging. When $\mathrm{Li}^{+}$ inserts into a single $\mathrm{FePO}_{4}$ phase particle during discharging, the $\mathrm{LiFePO}_{4}$ phase will be initially formed in the shell while the core remains as a $\mathrm{FePO}_{4}$ phase. The phase boundary keeps shrinking during discharging.

Some research groups question the suitability of core-shell models for single $\mathrm{LiFePO}_{4}$ particles because of several discrepancies between the assumptions of the model and experimental results $[32,34]$. First, $\mathrm{Li}^{+}$diffusion in $\mathrm{LiFePO}_{4}$ particles is confined in the b-direction anisotropically while the core-shell model assumes an isotropic radial $\mathrm{Li}^{+}$diffusion path. Second, the experiments indicate that the boundary of the second phase moves along the a-axis anisotropically while core-shell model assumes that the phase boundary moves along the radial direction isotropically. The core-shell model is suggested to be more suitable for describing a concentration growth at the scale of agglomerate particles, rather than a single particle [35]. Nevertheless, these models do not consider a twophase interfacial zone, where lithium-ion concentration varies within the zone, as observed experimentally [33-35]. Thus, the model developed in the current study has addressed $\mathrm{Li}^{+}$ diffusion anisotropy, and it is capable of evaluating $\mathrm{Li}^{+}$ concentration evolution in the interfacial zone, and could be utilized later to further study diffusion induced stress in a single $\mathrm{LiFePO}_{4}$ particle.

\section{CONCLUSION}

To our best knowledge, we herein present the first model to describe lithium-ion diffusion mechanisms in the two-phase interfacial zone. An anisotropic diffusion model is developed to quantify lithium concentrations in different channels during discharging. Our model reveals channels are fully filled progressively, which is in consistent with experimental observation. In addition, we are currently in the progress developing methods to quantify lithium-ion transport and the associated concentration profile via neutron scattering techniques. Therefore, our numerical model presented in the current study will be modified according to our measurements upon available. Furthermore, the model could be expanded to predict concentration profiles while (dis)charging rate is increased. The predicted concentration values will later be used to develop a model to study diffusion-induced stresses in lithium-ion batteries. This study helps explain the diffusion process in a single $\mathrm{LiFePO}_{4}$ particle, specifically in the twophase interfacial zone. The result of the study will contribute to the design of more reliable lithium-ion batteries.

\section{REFERENCES}

[1] Office of Atmospheric Programs, 2010, "EPA Analysis of the American Power Act," U.S. Environmental Protection Agency.

[2] Environmental Protection Agency and Department of Transportation, 2011, "2017-2025 Model Year Light-Duty Vehicle Greenhouse Gas Emissions and Corporate Average Fuel Economy Standards," Federal Register, 76(153) .

[3] U.S. Energy Information Administration, 2012, "April 2012 Monthly Energy Review," U.S. Department of Energy, DOE/EIA-0035, Washington, D.C.

[4] S. C. Davis, S. W. Diegel, R. G. Boundy, 2011, "Transportation Energy Data Book 30th Edition," U.S. Department of Energy, Washington, DC.

[5] Chiang, Y., 2010, "Building a Better Battery," Science, 330(6010) pp. 1485-1486.

[6] Kang, B., and Ceder, G., 2009, "Battery Materials for Ultrafast Charging and Discharging," Nature, 458(7235) pp. 190-193.

[7] Zhang, Y., Wang, C., and Tang, X., 2011, "Cycling Degradation of an Automotive LiFePO(4) Lithium-Ion Battery," Journal of Power Sources, 196(3) pp. 1513-1520.

[8] Yuan, L., Wang, Z., Zhang, W., 2011, "Development and Challenges of LiFePO4 Cathode Material for Lithium-Ion Batteries," Energy \& Environmental Science, 4(2) pp. 269-284. [9] Yixu Wang, 2011, "Lithium-Ion Battery Cathode Materials Structure Failure Investigation," .

[10] Park, M., Zhang, X., Chung, M., 2010, "A Review of Conduction Phenomena in Li-Ion Batteries," Journal of Power Sources, 195(24) pp. 7904-7929.

[11] Chung, S., Bloking, J., and Chiang, Y., 2002, "Electronically Conductive Phospho-Olivines as Lithium Storage Electrodes," Nature Materials, 1(2) pp. 123-128.

[12] Chung, S., Bloking, J., and Chiang, Y., 2003, "From our Readers - on the Electronic Conductivity of Phosphoolivines as 
Lithium Storage Electrodes - Reply," Nature Materials, 2(11) pp. 702-703.

[13] Zhang, W., 2011, "Structure and Performance of LiFePO(4) Cathode Materials: A Review," Journal of Power Sources, 196(6) pp. 2962-2970.

[14] Boulfelfel, S. E., Seifert, G., and Leoni, S., 2011, "Atomistic Investigation of $\mathrm{Li}+$ Diffusion Pathways in the Olivine LiFePO4 Cathode Material," Journal of Materials Chemistry, 21(41) pp. 16365-16372.

[15] Nishimura, S., Kobayashi, G., Ohoyama, K., 2008, "Experimental Visualization of Lithium Diffusion in Li(x)FePO(4) RID B-2754-2011 RID A-4920-2011," Nature Materials, 7(9) pp. 707-711.

[16] Dathar, G. K. P., Sheppard, D., Stevenson, K. J., 2011, "Calculations of Li-Ion Diffusion in Olivine Phosphates," Chemistry of Materials, 23(17) pp. 4032-4037.

[17] Yang, J., and Tse, J. S., 2011, "Li Ion Diffusion Mechanisms in LiFePO(4): An Ab Initio Molecular Dynamics Study," Journal of Physical Chemistry a, 115(45) pp. 1304513049.

[18] Malik, R., Burch, D., Bazant, M., 2010, "Particle Size Dependence of the Ionic Diffusivity," Nano Letters, 10(10) pp. 4123-4127.

[19] Srinivasan, V., and Newman, J., 2004, "Discharge Model for the Lithium Iron-Phosphate Electrode RID B-8650-2008," Journal of the Electrochemical Society, 151(10) pp. A1517A 1529.

[20] Delacourt, C., Poizot, P., Levasseur, S., 2006, "Size Effects on Carbon-Free LiFePO4 Powders," Electrochemical and Solid State Letters, 9(7) pp. A352-A355.

[21] Meethong, N., Huang, H. S., Carter, W. C., 2007, "SizeDependent Lithium Miscibility Gap in Nanoscale Li1xFePO4," Electrochemical and Solid State Letters, 10(5) pp. A134-A138.

[22] Kobayashi, G., Nishimura, S., Park, M., 2009, "Isolation of Solid Solution Phases in Size-Controlled Li(x)FePO(4) at Room Temperature RID B-2754-2011 RID A-4920-2011," Advanced Functional Materials, 19(3) pp. 395-403.

[23] Wagemaker, M., Singh, D. P., Borghols, W. J. H., 2011, "Dynamic Solubility Limits in Nanosized Olivine LiFePO(4)," Journal of the American Chemical Society, 133(26) pp. 1022210228 .

[24] Bai, P., Cogswell, D. A., and Bazant, M. Z., 2011, "Suppression of Phase Separation in LiFePO(4) Nanoparticles during Battery Discharge," Nano Letters, 11(11) pp. 4890-4896. [25] Malik, R., Zhou, F., and Ceder, G., 2011, "Kinetics of Non-Equilibrium Lithium Incorporation in LiFePO(4)," Nature Materials, 10(8) pp. 587-590.

[26] Meethong, N., Kao, Y., Tang, M., 2008, "Electrochemically Induced Phase Transformation in Nanoscale Olivines Li1-xMPO4 (M = Fe, Mn)," Chemistry of Materials, 20(19) pp. 6189-6198.

[27] Gu, L., Zhu, C., Li, H., 2011, "Direct Observation of Lithium Staging in Partially Delithiated LiFePO4 at Atomic Resolution," Journal of the American Chemical Society, 133(13) pp. 4661-4663.
[28] Dodd, J., Yazami, R., and Fultz, B., 2006, "Phase Diagram of Li(x)FePO4," Electrochemical and Solid State Letters, 9(3) pp. A151-A155.

[29] Delacourt, C., Poizot, P., Tarascon, J., 2005, "The Existence of a Temperature-Driven Solid Solution in LixFePO4 for $0<=\mathrm{x}<=1$," Nature Materials, 4(3) pp. 254-260.

[30] Rousse, G., Rodriguez-Carvajal, J., Patoux, S., 2003, "Magnetic Structures of the Triphylite LiFePO(4) and of its Delithiated Form FePO(4)," Chemistry of Materials, 15(21) pp. 4082-4090.

[31] Tang, M., Belak, J. F., and Dorr, M. R., 2011, "Anisotropic Phase Boundary Morphology in Nanoscale Olivine Electrode Particles," Journal of Physical Chemistry C, 115(11) pp. 4922-4926.

[32] Laffont, L., Delacourt, C., Gibot, P., 2006, "Study of the LiFePO4/FePO4 Two-Phase System by High-Resolution Electron Energy Loss Spectroscopy," Chemistry of Materials, 18(23) pp. 5520-5529.

[33] Chen, G. Y., Song, X. Y., and Richardson, T. J., 2006, "Electron Microscopy Study of the LiFePO4 to FePO4 Phase Transition," Electrochemical and Solid State Letters, 9(6) pp. A295-A298.

[34] Ramana, C. V., Mauger, A., Gendron, F., 2009, "Study of the Li-insertion/extraction Process in $\mathrm{LiFePO}(4) / \mathrm{FePO}(4), "$ Journal of Power Sources, 187(2) pp. 555-564.

[35] Brunetti, G., Robert, D., Bayle-Guillemaud, P., 2011, "Confirmation of the Domino-Cascade Model by LiFePO4/FePO4 Precession Electron Diffraction," Chemistry of Materials, 23(20) pp. 4515-4524.

[36] Delmas, C., Maccario, M., Croguennec, L., 2008, "Lithium Deintercalation in LiFePO(4) Nanoparticles Via a DominoCascade Model RID G-6492-2011," Nature Materials, 7(8) pp. 665-671.

[37] Cogswell, D. A., and Bazant, M. Z., 2012, "Coherency Strain and the Kinetics of Phase Separation in LiFePO4 Nanoparticles," Acs Nano, 6(3) pp. 2215-2225.

[38] Van der Ven, A., Garikipati, K., Kim, S., 2009, "The Role of Coherency Strains on Phase Stability in $\mathrm{Li}(\mathrm{x}) \mathrm{FePO}(4)$ : Needle Crystallites Minimize Coherency Strain and Overpotential," Journal of the Electrochemical Society, 156(11) pp. A949-A957.

[39] Meethong, N., Huang, H. S., Speakman, S. A., 2007, "Strain Accommodation during Phase Transformations in Olivine-Based Cathodes as a Materials Selection Criterion for High-Power Rechargeable Batteries," Advanced Functional Materials, 17(7) pp. 1115-1123.

[40] Tang, M., Carter, W. C., and Chiang, Y., 2010, "Electrochemically Driven Phase Transitions in Insertion Electrodes Or Lithium-Ion Batteries: Examples in Lithium Metal Phosphate Olivines," Annual Review of Materials Research, Vol 40, 40pp. 501-529.

[41] Zhang, X., Shyy, W., and Sastry, A. M., 2007, "Numerical Simulation of Intercalation-Induced Stress in Li-Ion Battery Electrode Particles," Journal of the Electrochemical Society, 154(10) pp. A910-A916. 
[42] Zhao, K., Pharr, M., Cai, S., 2011, "Large Plastic Deformation in High-Capacity Lithium-Ion Batteries Caused by Charge and Discharge RID F-8640-2010 RID G-39192010," Journal of the American Ceramic Society, 94pp. S226$\mathrm{S} 235$.

[43] Kalnaus, S., Rhodes, K., and Daniel, C., 2011, "A Study of Lithium Ion Intercalation Induced Fracture of Silicon Particles used as Anode Material in Li-Ion Battery," Journal of Power Sources, 196(19) pp. 8116-8124.

[44] Cheng, Y., and Verbrugge, M. W., 2009, "Evolution of Stress within a Spherical Insertion Electrode Particle Under Potentiostatic and Galvanostatic Operation," Journal of Power Sources, 190(2) pp. 453-460.

[45] Jagannathan, K., 2009, "Approximate Solution Methods for Solid-State Diffusion in Phase-Change Electrodes," Journal of the Electrochemical Society, 156(12) pp. A1028-A1033.

[46] Jagannathan, K., and Raghunathan, K., 2012, "ChargeDischarge Asymmetry of Phase Change Electrodes from Isotropic Solid State Diffusion Models," Journal of the Electrochemical Society, 159(1) pp. A26-A37.

[47] Zhang, X., Sastry, A. M., and Shyy, W., 2008, "Intercalation-Induced Stress and Heat Generation within Single Lithium-Ion Battery Cathode Particles," Journal of the Electrochemical Society, 155(7) pp. A542-A552.

[48] Park, J., Lu, W., and Sastry, A. M., 2011, "Numerical Simulation of Stress Evolution in Lithium Manganese Dioxide Particles due to Coupled Phase Transition and Intercalation," Journal of the Electrochemical Society, 158(2) pp. A201-A206. 